\title{
The Impact of Occupational Stress on Employees' Performance and Customer Value Creation: Case of an American Multinational Company Subsidiary in Morocco
}

\author{
Raissoune Bajji \\ Ibn Tofaill University \\ Kaouter Abdelfadel \\ Mohamed V University of Rabat \\ Morad Sbiti
Mohamed V University of Rabat \\ Siham Lalaoui \\ Ibn Tofaill University
}

This paper intends to determine the extent to which occupational stress impacts individual performance, and whether it affects the customer value creation. The objective is to shine new light on the occupational stress challenges through examining an American multinational company based in Morocco. Therefore, the key question of this study asks the way the occupational stress affects individual performance, and consequently, customer value. A qualitative methodology is adopted and a specific interview guide was developed. The main finding shows a high level of customer value creation is only possible through ensuring a non-stressful working environment, a prerequisite for employees' performance.

Keywords: performance, occupational stress, customer value, American multinationals, Morocco

\section{INTRODUCTION}

Since the late 1980s, enhancing the attractiveness of countries for foreign investments has become the new imperative of industrial policies (Michalet, 1999). In a worldwide level, there is a foreign investments competition especially as developing countries are eager to seize the opportunity and play a major role attracting the investing countries. In the current context of globalization, the improvement of the attractivity of the economy and the mobilization of foreign direct investment represent the most relevant element of growth and integration strategy in the international economic system.

Nowadays, the matter of foreign direct investment has become an important consideration in a country like Morocco. Morocco enjoys several competitive advantages that open the market to foreigners. Morocco enjoys financial, political and economic stability, and has a large market size. Due to its strategic geographical position, its important natural resources, its accessible and competent labor cost, as well as 
many other advantages, Morocco has become since the 90s a magnet for foreign investments. Morocco attracts especially European countries such as France in the first place and Spain in the second place, due to their geographical proximity, and then the United Arab Emirates. For this purpose, Morocco adopted an open market strategy that boosts foreign investment in the local economy, assists its modernization process and wins other countries as foreign investors such as the United Stated of America, Japan and Germany.

When the investment takes place with the foreign country, the company brings in its organizational values, structures, work methodology, professional development and trainings. Morocco not only sees the foreigners as a money entry, but also as a developing tool for the graduated population. For the multinationals themselves, the objective in setting up in developing countries is to reduce their costs by training their employees, by providing attractive salaries comparing to the national companies, and by offering a clear internal structure and strong hierarchy allowing skills development (Rabhi, 2009). Therefore, the foreign investments are trying to reach their maximum performance with lower costs.

Organizational performance involves analyzing how a company is doing compared to what its objectives and goals were. It focuses on three main outcomes: shareholder value (focus on the customer and employee), the financial performance and the market performance. Most authors define the term as a similar meaning to organizational effectiveness. However, organizational effectiveness covers a broader area. Performance is commonly defined as the process or action of performing a function or task. When we put the term performance and organization together, they mean how successfully an organized group of people with a specific purpose perform a function.

Every organization is a behavioral system at its most fundamental level (Tosti \& Herbst, 2009). Organizations are led by people for the needs of people: owners, employees, customers, and shareholders. All the stakeholders have roles in the process and in the performance of an organization. Commonly, the environment principle is an essential parameter in developing behavior system models by analysts (Glenn \& Malott, 2004). An organization is performant when several efficient dimensions are put together. An organization reaches its performance when financial aspects and non-financial aspects are both satisfied. Obviously, without the non-financial aspects, organizations cannot access its financial objectives. In this regard, the multinational companies must take into consideration every detail of the well-being of the stakeholders.

Unfortunately, the employees' well-being has been severely deteriorated lately. Along with the declined well-being, a new organizational risk has been widespread: psychosocial risks. Psychosocial risks refer to the risks resulting from the psychological interaction of a person with his or her social environment. Those risks outcome from a bad conjunction between work design and management (Cox, et al., 2000).

The literature groups together four main categories of psychosocial risks which are: work demands and work organization, management and work relations, employees' values and expectations, and changes at work. These factors have the particularity of undermining occupational health and generating, consequently, immeasurable costs for the organizations. Psychosocial risk is thus a situation that might lead to discomfort or suffer in the workplace.

Accordingly, occupational stress, anxiety disorders, suffering, burnout, moral and sexual harassment, external and internal violence are all psychosocial risks. In this article, particular attention will be devoted to the most prevalent risk: the occupational stress.

The point of this article is to enlighten the reader on the relevance of the non-financial aspects such as the employee and the customer's satisfaction and its impact on the overall organizational performance. But more particularly, this research focuses on the occupational stress and its impact on the individual performance in the case of an American multinational company subsidiarized in Morocco and how this individual performance affects the customer value creation.

In this article, we target the B-to-B customer value within an organization which has psychosocial risks among its employees. Therefore, the key research question of this study is whether the occupational stress impacts the individual employee performance or not, and how does it affects the customer value?

Thus, this study aims to contribute to the growing area of researches concerning the work-related stress in Morocco, a country with a huge lack of studies about employees' mental health. And through this 
investigation, the main purpose is to assess the risks associated with a high preponderance of occupational stress.

This article seeks to provide answers to the research problematic first by reviewing the existing literature. Thereby, the paper gives an overview over the main key concepts of the study which are: occupational stress and customer value. The remaining parts of this paper focuses on the methodology of the study which is a qualitative analysis. Once the empirical findings analyzed and discussed, the final part outlines the organizational implications, the revealed limitations and draws the study conclusion.

\section{THEORETICAL FRAMEWORK AND LITERATURE REVIEW}

\section{Linking Customer Value and Performance}

In a perfect world, according to Tosti and Herbst, the customer value involves the perception of the service or the product against the cost and effort done to purchase it (Tosti \& Herbst, 2009). But in the real world, things are not that easy to apply. In fact, when the customer experience is going wrong, the cost side of the transaction is questioned in the process. Even if the customer value and experience is high and the process goes undoubtedly without failing, a lot of dimensions can be targeted for improvement. And thus, this is how organizations can improve customer value.

A considerable amount of literature has been published about the work performance. These studies are nowadays the most relevant performance models. The table below summarizes the performance models, their definitions, and their authors:

\section{TABLE 1}

\section{CLASSIC PERFORMANCE MODELS}

\begin{tabular}{|c|c|c|}
\hline Performance models & About the model & Authors \\
\hline $\begin{array}{l}\text { The performance } \\
\text { pyramid }\end{array}$ & $\begin{array}{l}\text { The model is a four-level performance pyramid that links the } \\
\text { corporate strategy with the operations through the hierarchy by } \\
\text { translating objectives from the top and measures from the } \\
\text { bottom. }\end{array}$ & $\begin{array}{l}\text { (Lynch \& } \\
\text { Cross, 1991) }\end{array}$ \\
\hline $\begin{array}{l}\text { The Results and } \\
\text { Determinants } \\
\text { Framework }\end{array}$ & $\begin{array}{l}\text { The framework creates a link between present business } \\
\text { performances as reflected by results with the business } \\
\text { performance of the past as measured by the determinants. }\end{array}$ & $\begin{array}{l}\text { (Fitzgerald, } \\
\text { Johnston, } \\
\text { Brignall, } \\
\text { Silvestro, \& } \\
\text { Voss., 1991) }\end{array}$ \\
\hline Balanced Scorecard & $\begin{array}{l}\text { This model is the most popular one. It is a system that } \\
\text { combines both financial and non-financial measure. It allows } \\
\text { the organization to align the business performance with } \\
\text { strategy, aiming its success in the market. }\end{array}$ & $\begin{array}{l}\text { (Kaplan \& } \\
\text { Norton, } \\
\text { 1992) }\end{array}$ \\
\hline $\begin{array}{l}\text { Areas of } \\
\text { organizational } \\
\text { performance }\end{array}$ & $\begin{array}{l}\text { This model summarizes several key performance indicators in } \\
\text { every area of performance (sustainability, legitimacy, } \\
\text { economic efficiency and Human resources value) and the fifth } \\
\text { area is defined as the political one. All these areas combined } \\
\text { can lead to the overall organizational performance. }\end{array}$ & $\begin{array}{l}\text { (Morin, et al. } \\
\text { 1994) }\end{array}$ \\
\hline $\begin{array}{l}\text { A stakeholder } \\
\text { approach to strategic } \\
\text { performance } \\
\text { measurement }\end{array}$ & $\begin{array}{l}\text { This model focuses equally on the role and value of every } \\
\text { stakeholder in the company such as the employees, the } \\
\text { customers, the suppliers and the community. }\end{array}$ & $\begin{array}{l}\text { (Atkinson, } \\
\text { Waterhouse, } \\
\text { \& Wells, } \\
\text { 1997) }\end{array}$ \\
\hline $\begin{array}{l}\text { Performance based } \\
\text { model of customer } \\
\text { value }\end{array}$ & $\begin{array}{l}\text { This model demonstrates how the internal behavioral system } \\
\text { impacts the value of the organization and its brand image. They } \\
\text { presented a seven-phased model targeting the alignment of the }\end{array}$ & $\begin{array}{l}\text { (Tosti \& } \\
\text { Herbst, 2009) }\end{array}$ \\
\hline
\end{tabular}


organization with customer values: performance analysis, senior and middle management orientation, communicating the value to all employees, feedback sessions, employees direct planning and implementation of brand alignment, and a maintenance phase.

Value creation and The main objective of this model is linking the seller's firm sales performance with the created value for the customers. The key

(Sullivan, et al., 2012)

performance component is the strategic account management and its relationship between the buyer and the seller mediated effect of value creation on performance.

All these authors and researches have framed the organizational performance in four important topics which are the organizational sustainability, economic efficiency, human resources value, and the customer value. In each model, the authors highlighted the importance of the employees and the customers in the organizational performance.

Most organizations and performance models are focused on the customer. From this assumption, it is possible to say that the processes and the internal practices are oriented to maximize the customer value by dint of their products and /or services. All the services are experiences for the customer (Tosti \& Herbst, 2009).

Managing the customer value within a company requires key performance indicators. These indicators can be defined as the physical values which are used to measure, compare and manage the overall organizational performance (Gosselin, 2005). The key performance indicators measuring the overall performance of the organization are quality ( (De Toni \& Tonchia, 2001), (Gosselin, 2005), (Heckl \& Moormann, 2010), (Badri, et al., 1994), (Neely, et al., 2005)), delivery reliability ( (White, 1996), (Heckl \& Moormann, 2010), (Neely, et al., 2005), (De Toni \& Tonchia, 2001), (Mapes, et al., 1997)), employee's satisfaction ( (Leong, et al., 1990), (Mapes, et al., 1997), (Parmenter, 2009)), customer satisfaction ( (Ittner \& Larcker, 1998), (Neely, et al., 2005) (Parmenter, 2009)), environment and community ( (Neely, et al., 2005) (Parmenter, 2009) (White, 1996)).

The studies of Bhatti have shown the importance of the customer satisfaction and delivery reliability in the organizational performance (Bhatti, et al., 2014). It is hard to keep customers if a company's delivery doesn't live up to its brand promise (Tosti \& Herbst, 2009). Even if there is a discrepancy between the authors about the measures of the delivery reliability, their studies have shown a great correlation between delivery reliability, customer satisfaction and performance.

To satisfy the needs of the customer and increase the value of the company, there is a fundamental key of success which is the employee. The employees are the driving force of a company (Atkinson, Waterhouse, \& Wells, 1997). Human capital is special and unique because it is immaterial. It is through the combination of knowledge and skills that organizations can develop the organizational commitment of its employees, and therefore, create a dynamic approach to performance. The satisfaction of the employee impacts positively the customer satisfaction and the organizational performance ((Leong, et al., 1990) (Mapes, et al., 1997) (Parmenter, 2009)).

The model of Tosti and Herbst, not only increases the customer value, but also the employee's value (Tosti \& Herbst, 2009). When the employee has an ambient work environment and strong relationships, it has a direct consequence on a higher morale. The responsibility not only lies in the competencies, training and behaviors of the employees, but involves also the managerial board where the management board consist on the senior and middle management. The top management works actively in supporting the team and the employees and the middle management is involved in the day-to-day leadership.

Hypothesis 1 (H1): A lower employee's satisfaction may decrease the customer value creation.

Hypothesis 1.a (H1.a): The mid-management has a significant impact on the employee's satisfaction and his productivity. 
Hypothesis 1.b (H1.b): Delayed delivery increases the customer value creation.

Hypothesis 1.c (H1.c): A low service's quality decreases the customer value creation.

\section{Stress Underpinnings}

Over the years, the term stress was defined in several ways, depending on the discipline in which it interfered. The term stress has been developed through its intervention in different disciplinary fields including physics, medicine, psychology and sociology. It first meant the load undergone by a spring which causes the tension of this body (stress) and its deformation (Hooke, 1678). And it was in the 1930s that the term stress was used for the first time by Hans Selye in a biological context. The author defines stress as an inappropriate physiological response to any environmental demand (Selye, 1956).

Different approaches have attempted to figure out the underlying of stress. Besides the biological approach developed by Hans Selye, the transactional approach presents stress as an imbalance that happens during the transaction between the person and his environment (Lazarus \& Folkman, 1984). This imbalance means that a misfit occurs between the environmental demands and the personal resources available to meet them. After all, stress has been defined as a pattern of physical and emotional responses expressed by the body when an imbalance is identified between environmental demands and available resources to fulfill them.

Later on, the interactional approach involves environment, context and individual in the comprehension of stress. Theorists argues that it is the interaction between the demands of the work environment and the control that the individual can exercise over these demands that generate stress. Thereby the Karasek model crosses two parameters to explain the stress occurrence through the evaluation of the psychosocial conditions prevailing in the workplace (Karasek, 1979). Therefore, Karasek analyses the relation between the job demand and the job control in order to assess the psychological load of the work. That's how Karasek distinguishes between four types of work that are: passive work, high strain work, low strain work and active work.

The first parameter which is "height of strain" or "job demand" refers to the physical, intellectual and emotional demands related to the amount of work required. This work's requirements may be the work load, the time pressure, the role ambiguity and the skill mobilized. The second parameter which is the "decision latitude" or "job control" refers to the degree of control that an employee has over his own work. The decision latitude includes the ability to use one's own knowledge at work, in addition to the autonomy in the decision-making regarding one's organization and execution of his work.

Hence, stress is triggered by stressors which are numerous environmental stimuli that lead to cognitive, physiological, biochemical and behavioral responses (Cox, 1993). When facing a stressful situation, the person adopts various adjustment strategies and adaptive responses. Coping responses are various cognitive and behavioral efforts engaged to manage internal or external demands assessed as threatening or exceeding one's resources (Lazarus \& Folkman, 1988).

Coping behaviors are meant either to fight or to flight the environment threats. In other words, coping strategies may be mobilized either to limit, control, or simply accept the environment threat. Ability to cope with challenging and stressful situations depends on the one's own perception of his abilities to cope. Three coping strategies can be engaged and are: problem-focused strategy (coping oriented towards solving the problem), emotion-focused strategy (coping oriented towards managing the induced emotions), and support-seeking strategy (coping oriented towards seeking social support) (Lazarus \& Folkman, 1984).

\section{Occupational Stress and Performance}

Within the last century, significant changes occurred and disrupted the commonly accepted work characteristics. Accordingly, those changes introduced a new phenomenon into the work place which is the occupational stress. The occupational stress is commonly defined as a misfit between the job requirements and the employees' needs and capacities. Work related stress shows off when one is exposed to stressors arising from the nature or from the organization of the work. 
Actually, occupational stress does not have a specific independent reason. It is more appropriately the result of the combination and the accumulation of several stressful factors over the time. Those factors may be intrinsic to the job's condition, relative to the role in the organization, or relative to the organization's environment, or as a result of personal perceptions (Arnold, et al., 1991). Concretely, the organizational stressors might be: poor working conditions, work schedules, work organization, interpersonal conflicts, role ambiguity, work overload, lack of control, job insecurity (Cox, et al., 2000).

Several authors state that certain individual factors moderate the perception of stressors. Each subject undertakes a cognitive evaluation, often unconscious, of the stakes of the situation deemed stressful. Otherwise, the harmfulness of a stressor depends on how the individual evaluate the severity of a threatening event. Two evaluations take place: the primary appraisal where the person make a subjective assessment of the situation, and the secondary appraisal where the person examines the available response options (Lazarus \& Folkman, 1984). Thus, the stress process depends on subjective considerations specific to each subject. Those individual factors include: personality (Lazarus, 1995), locus of control (Rotter, 1966), gender issues (Kauppinen, et al., 2003), culture (Lazarus, 1995), previous experiences (Savoie \& Forget, 1983), interpersonal relationships (Savoie \& Forget, 1983) and finally whether or not it is important for the person to meet the environmental demand (Savoie \& Forget, 1983).

In addition, some social factors related to the organization's social environment can be identified. It may be the crumbling of institutions, the macro-economic situation and the recurrence of crises, the imperative of performance, the instability and the obligation of mobility, the contraction of time, and the fragility of relational commitments (Lefebvre \& Poirot, 2015).

Hypothesis 2 (H2): The working environment does have a significant impact on the perceived work stress.

Hypothesis 2.a (H2.a): Poor working conditions contribute to an overall stressful work environment.

Hypothesis 2.b (H2.b): The work organization contributes to an overall stressful work environment.

It is now commonly known that work-stress causes harmful reactions, both at the psychological level and the physical level. We distinguish four types of effects:

- Physiological effects are caused by metabolic changes due to a stressor exposure as cardiovascular disease, blood pressure problems, diabetes, ulcers, chest pains, headaches, musculoskeletal disorders, immune troubles and even high risks of developing cancers (Grippo \& Johnson, 2009);

- Various emotional effects are caused by an important exposure to stress and can be revealed by numerous symptoms as important fatigue, sadness, altered mood, irritability, nervousness, depression, anxiety, burnout (Godin, et al., 2005);

- Regarding the behavioral effects, the subject engages unhealthy behaviors and attitudes to appease himself as bulimic tendency or appetite loss, insomnia or oversleeping, consumption of stimulants, alcoholism, smoking, consumption of sedatives or anxiolytics, and the use of psychotropic drugs (Mental Health Foundation, 2018), or may develop nervousness, violence and withdrawal behaviors (Quick, et al., 1997);

- Cognitive effects are due to the body's pains that lead to cognitive problems as concentration difficulties, troubles in the making decision process, memorization difficulties, carelessness, intolerance to criticism and job dissatisfaction (Quick, et al., 1997).

After all, stress causes many damages to one's health with an interaction and a combination effect between them. Prolonged exposure to stress leads to different type of effects and the body's pain becomes noticeable. As a result, employees are obliged to seek medical care and to support important health care costs.

Furthermore, performance is the result of three main parameters which are the ability to do the demanded work, the level of effort needed and the support given to the subject (Mathis \& Jackson, 2000). 
The variation of one of these parameters produces variations in the employee's productivity level. Due to a deteriorated health, employees' ability to do the demanded work tends to decrease, and so does the productivity. Destructive impacts on the employees' performance occur leading to a performance decline, absenteeism increase, presenteeism increase, grievances increase, motivation decrease and turnover increase.

Those consequences are related to the fact that employees tend to reduce the quality and the quantity of their productivity. Therefore, the organization is compelled to support the cost of a poor health at work due to occupational stress, the cost of a declining organizational performance, as well as the cost of the nonperformed work leading to profits lost (Thompson \& McHugh, 1995).

Hypothesis 3 (H3): An important perceived occupational stress leads to an individual performance deficiency.

In view of all the literature review that has been mentioned so far, the conceptual model adopted by this paper is schematized as follows:

\section{FIGURE 1}

\section{THE CONCEPTUAL MODEL}

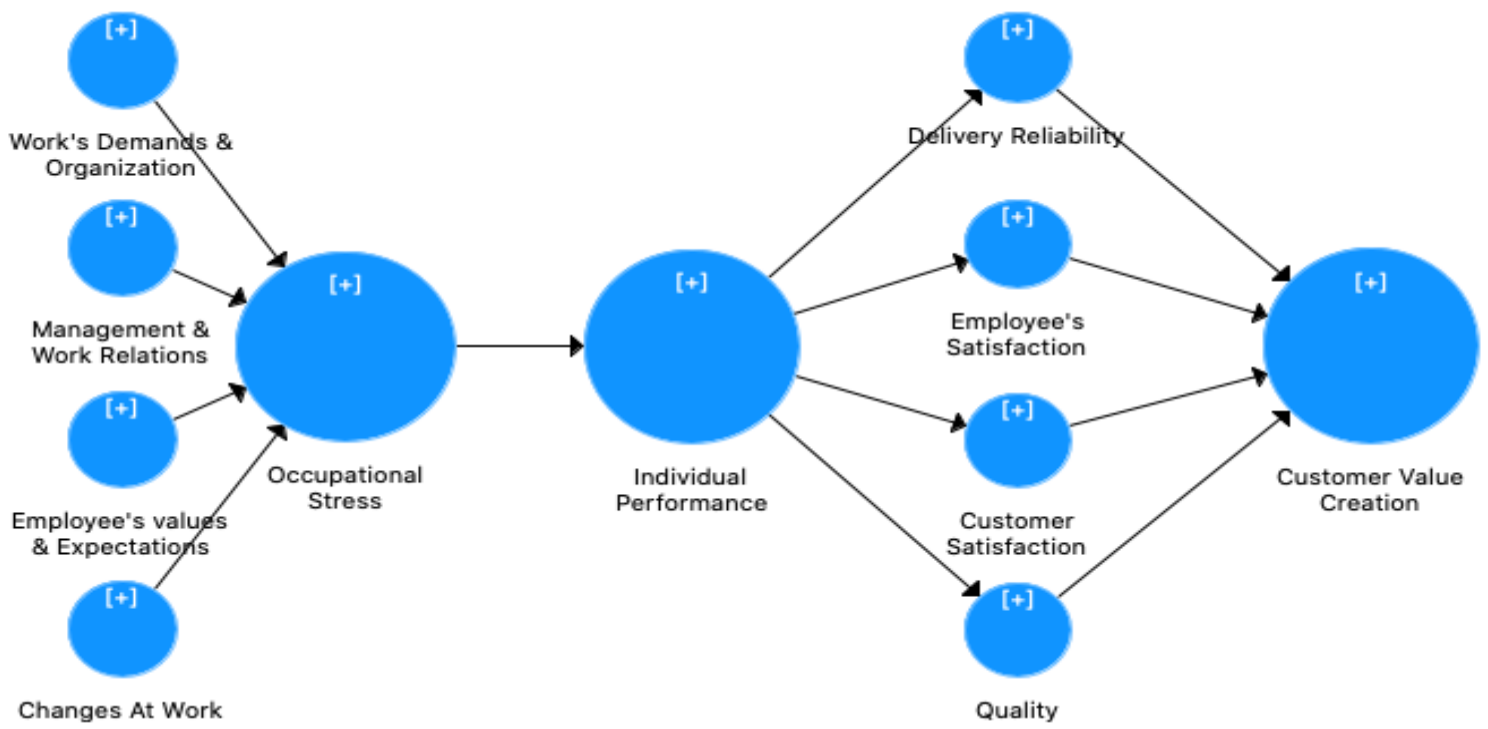

\section{PSYCHOSOCIAL RISKS IN THE U.S WORK ENVIRONMENT: A FOCUS ON STRESS}

Ensuring the health and safety of employees is a long-standing obligation owed by the employers. Beyond their managerial responsibilities, organizations have a legal and penal responsibility to provide a healthy and psychosocial risk-free workplace. Thus, psychosocial risks involve public health issues, as well as economic, social and legal responsibilities.

Regarding work-related stress, one of the most common psychosocial risk at work, legal texts condemn reckless management practices that generate a stressful work environment. This consideration is formalized by the institutionalization of the occupational stress in collective agreements, in labor laws, in decrees, in collective conventions, in the creation of structures dedicated to working conditions or in voluntary guidelines (International Labour Organization, 2006).

Mental health in the workplace is widely taken seriously in the US. And in order to prove to which point occupational stress is damaging, several studies have been conducted in the American context. According to the American Institute of Stress, one million workers miss their work every day because of 
work-related stress (The American Institute of Stress, 2019). In addition, the Everest College says that $83 \%$ of the American employees suffer from stress at work (Everest College, 2009). Moreover, 300 billion dollar is lost each year by the US businesses as a result of a stressful workplace (The American Institute of Stress, 2019).

While stress is unavoidable, reducing its somatic and emotional effects is highly recommended. That's why developing programs to manage and support mental health in the workplace is a priority in the US. The National Institute for Occupational Safety and Health (NIOSH) claims that reaching a low rate of illness, disability and injury in the workplace requires some organizational actions as (NIOSH, 2014):

- Recognition of a good work performance;

- Organizational practices that value the individual employee;

- Ensure stimulation of the employees' skills and opportunities for career development;

- Stress management training and employee assistance program;

- Improving job design and working condition;

- Develop a stress prevention program.

From now on, it is no longer a question of recognizing or not recognizing stress at work: it has been made a legal obligation. Establishing law programs aims to raise awareness regarding legal implications of manager toward work-place stressors. In fact, it involves preventive law where the employer must identify the symptoms of an excessive stress level before it leads to psychological disturbance and physical illness.

The laws enable to minimize stress in the workplace and support the need of more actions toward it. That is what the general duty clause of the Occupational Safety and Health Act provides (Occupational Safety and Health Administration, 1970). Concretely, the clause gives guidance to create a stress-free working environment through occupational safety and health standards promulgated under the OSHA. Moreover, confirming that occupational stress carries a legal risk allows the employees to seek compensations for stress-related disability (Ivancevich, et al., 1985).

\section{PSYCHOSOCIAL RISKS IN THE MOROCCAN CONTEXT: A FOCUS ON STRESS}

The ILO states that each country must take the necessary actions through a national strategy of prevention of health and safety at work, and improvement of the socio-professional conditions of the working environment (International Labour Organization, 2006). The convention $\mathrm{n}^{\circ} 187$ on occupational safety and health has been ratified by Morocco. Morocco engages into the regulation of the work through the establishment of numerous dahir such as the dahir of July 2, 1947, on labor regulations, and the dahir of May 31, 1943, about occupational disease and work accidents.

The occupational health and safety is governed in Morocco by various ministries, by specialized institutional structures and by trade union organizations. However, the outdated nature of the legislative and regulatory mechanisms governing occupational health and safety in Morocco leads to several emerging risks not being considered.

In Morocco, occupational stress is one of the most widespread but least regulated risks. It is not included among the occupational diseases mentioned in the decree $n^{\circ} 919-99$ (Ministry of Social Development, Solidarity, Employment and Vocational Training, 1999). And yet, $44 \%$ of Moroccans claim to be in a bad state, $51 \%$ of which is caused by stress (Gallup, 2019). In addition, $48 \%$ of interviewees said that they had experienced too much stress the day before the survey, ranking Morocco 28th in the world according to the Gallup study.

Psychosocial risks are therefore neglected by the Moroccan Labor Code. For instance, the law $\mathrm{n}^{\circ} 65-99$ of the Moroccan Labor Code omits the psychological dimension related to the health of the employees (Morocco, 2003). In the end, although there is some awareness of the behavioral, emotional and cognitive manifestations of occupational stress, legal recognition is still lacking (Esserdi, et al., 2020).

But in response to the ILO Recommendation No. 197, Morocco has prepared the National Profile for Occupational Safety and Health, which is a complete report on its situation. Indeed, this report mentions all 
the forms of threats that Moroccan employees may face, but neglects once again to consider any psychosocial risks.

\section{CASE OF THE AMERICAN MULTINATIONAL COMPANY IN MOROCCO}

The American multinational company studied in this article was created in 1948 in the United States and has subsidiarized in Morocco since 1997. The business of this multinational is mainly the human resources management and all the human capital areas. In order to respect the ethical values, we prefer to keep the name of the organization anonymous.

This subsidiary is working on a project related to payroll control and auditing. This project is presented by a unit composed with one mid-manager in the head of hierarchy, followed by two team leaders managing their teams. Every team has an internal auditor who controls the work of the payroll controllers. The client is the same multinational but subsidiarized in France. Without any doubt, the project cost is lower than if the client chose another tax services office to do the job. We can truly compare this subsidiary to a manufacturing organization since it has objectives in terms of quality and quantity (delivering the service). And to be competitive in the markets, the manufacturing companies should offer a rapid variety (of service and products), and to produce quality with a lower cost. Thus, this is a valuable objective of the organization (Bhatti, et al., 2014). But at what cost?

The company offers a generous salary and a performant technology issued from a unique system prepared by a computer engineer operating in the headquarters in Morocco. Every employee has his own desk and session in his computer. And this session is load with the total payslip to control and dashboards. These dashboards are showing both individual and the team performance.

Every month there is a payroll control targeting the previous month, and every controller must detect the mistakes of five hundred sixty-two agencies in France. These agencies are due to pay taxes for every mistake in payslip if they accord a wrong compensation. The control is done in more than one thousand and six hundred payslips attributed to each employee. That said, it is a great load of work significant to an average of more than fifty document per day to control. If this number is shared over the eight hours of work, then every payslip must be controlled in fifteen minutes. Nevertheless, the controller must work in these fifteen minutes with several software (four software in every control) to check the authenticity of various information such as the salary address, the contract, the total non-taxable allowance, their compensation ceiling and so on. This work requires a lot of concentration, skills, knowledge and an excellent training.

\section{METHODOLOGY: A QUALITATIVE ANALYSIS}

Our research study is primarily based on an important step which is the observation. This research has begun with a three-year work experience within the American multinational where the author has been an employee. The author witnessed the overall process of payroll control, auditing and team leading. The field experience allowed to spot the struggles within this type of organization, thanks to which the analysis methodology has been identified.

Therefore, for this study, qualitative research interviews have been conducted in the company, based in the town of Casablanca, in Morocco. As the number of employees in the company is not enormous, our first goal was to interview every single employee except the mid management. Thus, the sample used in this study is a complete and representative sample which reflects the characteristics of the company and its richness. The study is based on a criterion sampling as the main and only pre-determined criteria is being employed in the studied case of the American multinational.

A total of sixteen employees has been interviewed without knowing beforehand if they are facing a stress situation at work and if they are satisfied with their job position and work environment, or not. The employees were contacted by phone and some by emails to take their approbation and book an interview appointment. Fortunately, all the employees accepted the collaboration and the interviews took place in the company locals in Casablanca. 
The interviewees were then invited to the study and the participation was fully voluntary. They were contacted in advance by phone and email to be informed about the aims and the nature of the study. Participants in different positions were recruited for a face-to-face interview. A total of sixteen respondents were involved in the survey (two team leaders, four auditors and ten payroll controllers).

Participants were asked to answer an interview guide consisting of six topics. These topics were about exploring the participants' experience of occupational stress at work, their job performance and their evaluation of the customer value.

\section{PROCEDURE AND DATA ANALYSIS}

Each meeting lasted at least thirty minutes and was set as a semi-structured interview. The interview guide can be found in the appendices. Seven of the participants were male, whereas nine were female. The interviewees had an average age ranging from twenty-six to thirty-two years.

After conducting the interviews, the data recorded on a digital audio recorder was transcribed verbatim. The transcription step has been made manually in a word file and then built in the Quirkos software. The collected data have been subject to a semantic and thematic analysis so as to identify the recurring patterns. This approach has led to the classification of the verbatim responses in different theoretical categories (key themes).

The analysis of the transcribed data was carried out using the Quirko Software for qualitative data, Excel sheets and Word documents. In order to analyze the raw data, we uploaded a word file to Quirko software and sorted out the answers and the themes as per codes (tags and labels for assigning units of meaning (Miles \& Huberman, 1994)). Each category refers to a different factor that influences the perceived stress level, and its impact on the job performance and on the customer value. The identification of each category in the various responses allowed estimating its frequency. In this research, the codes came in the form of sentences, phrases and whole paragraphs which have been sorted by themes. Below, the schemes generated by Quirko:

\section{FIGURE 2 \\ DIAGRAM OF THE INTERVIEW GUIDE TOPICS GENERATED BY QUIRKO}

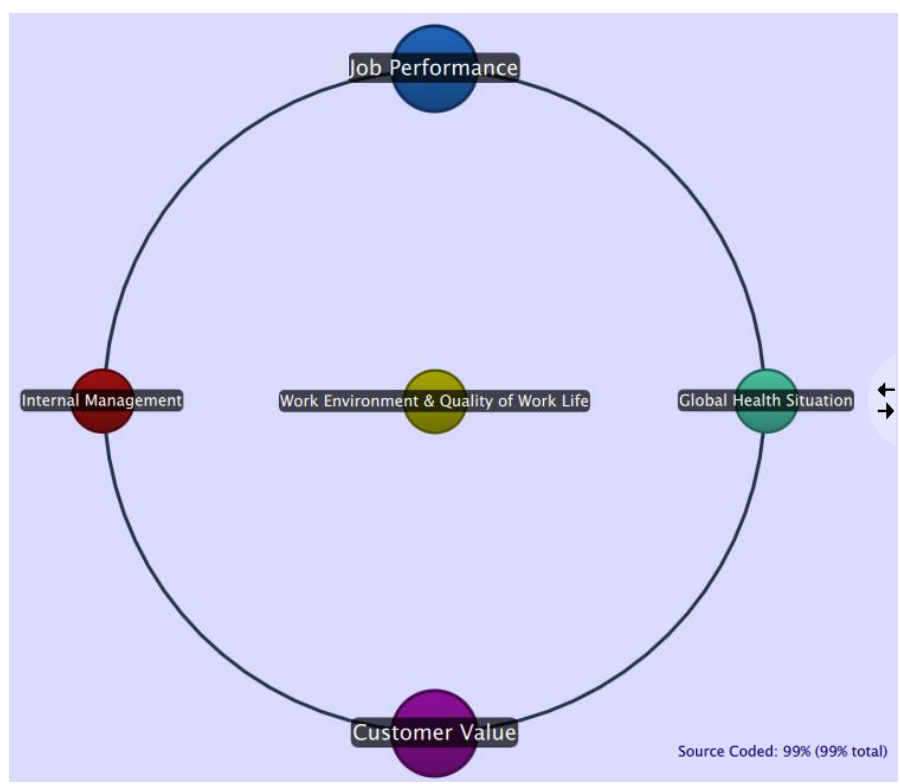




\section{RESULTS}

The results are presented below according to the outcomes of the data analysis. They are based on the major dimensions identified in the interviews. The significant findings that emerged were classified into three categories: the stressors (sources of occupational stress), the impact of occupational stress on job performance, and the impact of occupational stress on customer value.

Therefore, this section attempts to provide the elements of response to the research question states as follow: "Does the occupational stress impact the employees' performance and the customer value within organizations?".

\section{The Stressors}

All the sixteen participants were invited to give their opinion on their working conditions. The employees reported being not fully satisfied from their ambient working conditions (light, airiness, hygiene, sound environment, equipment, layout of the workspace, working climate). As one said: "The ambient conditions of my work are moderately satisfactory".

On the other side, employees stated that their workplace is frequently subject to interruptions and assaults (harassment, humiliation, violence, etc.). One individual specified that "The nature of my work means that I am often subject to recurring interruptions such as unforeseen requests and frequent team meetings", while another commented that "Assaults in my workplace are very common. You get disturbed too frequently. After each interruption, I have to start again thinking what was I doing before. And no sooner does the rhythm regain than another interruption occurs".

Almost all the interviewees expressed the belief that they suffer from a very intense pace of work. One participant commented: "I have a fast and sustained pace of work, everyday". In addition, employees are experiencing long and intense periods of concentration over various and simultaneous tasks. For example, one interviewee said: "My job consists of long and intense periods of concentration", and another added: "I have to keep my eye on various tasks at the same time".

Concerning the job demand, employees claim that their work is demanding intellectually and emotionally. As one interviewee put it: "What makes my work exhausting is above all a very strong intellectual mobilization, accompanied by a high emotional mobilization". Moreover, employees affirm that they depend on the pace at which their colleagues work. All agreed that "I sometimes find myself dependent on the pace at which my colleagues work", and that "Information sharing and communication are so often deficient".

Heading now to the role distribution, employees assert the existence of role incompatibilities and the obligation to shoulder the responsibilities of others every now and then. Interviewees, when asked, said: "Roles are not formally distinguished within my organization", "I do receive contradictory assignments", "Responsibilities are not fairly distributed within my organization".

More so, employees confirm that task role distribution is in some cases not equitable. He said: "I sometimes hold more responsibilities than I should, with some responsibilities that interfere with each other. Having to assume all of that causes me so much stress, especially when the task I don't feel competent in".

However, a divergent and conflicting discourse emerged from an employee who claimed that the organizational and structural objectives are clearly defined within the organization. He said: "I can say that the hierarchy make sure to well define and explain the several general objectives, but also the individual ones".

The social support provided by the employee's hierarchy is deemed insufficient. Employees reported having a limited instrumental support from the hierarchy (work techniques, supervision, solutions). In addition, no emotional support is provided by the superiors. In response to the question about the social support, interviewees indicated that "I rarely receive instrumental support from my hierarchy", and others added that "There is no emotional support coming from my superiors", "My superior doesn't care if I'm tired, discouraged or stressed". 
It is also reported that the superiors try to make sure to provide a qualitative support when needed. However, the majority claim that the hierarchy is not always available to give quantitative support when needed. One said: "My supervisor is not always available to provide me with quantitative support when needed".

In addition, the social support provided by the employee's colleagues is deemed sufficient. Employees reported having little instrumental support from the colleagues (work techniques, help, solutions) as well as the emotional support (support in dealing with any involved emotions). Participants commented as follow: "I do have now and then a support from colleagues when needed", "If necessary, I can say that I have emotional support from my colleagues", "I receive support from people of my social circle".

Regarding social relationships, employees stated that relationships between colleagues are mostly good, but with a lot of rivalry. Some interviewees argued that "Relations between colleagues are generally good, but incidents often occur", while others said that "Rivalry is very common in my work team", "Here, employees tend to stress each other", "Some colleagues do not recognize their responsibility for a work situation that has gone wrong".

The overall response to the question about the job control was that the organization offers very limited job control possibilities. The majority of those who responded to this item commented that: "My work offers a low degree of autonomy", "My work doesn't allow me to participate in decision-making", "I do not have the possibility to have control over my working methods", "I have a limited say in my team", "It makes me feel frustrated to know that my opinion don't count".

Moreover, no flexibility is allowed, especially in the working methods that can be adopted by employees. That's why some said: "I don't have the possibility to manage my working time", while others said "My work does not offer flexibility in terms of working hours, nor in terms of tasks, and allows even less flexibility in the methods that can be adopted".

In terms of rewards, the material rewards (in term of remuneration, bonus or salary increase) and the non-material reward (in term of congratulations, thanks, considerations, esteem and prospects for promotion) offered by the organization are deemed insufficient. For example, interviewees said: "The intangible and non-material reward are unsuitable for my efforts", "The efforts provided exceed the intangible rewards perceived in terms of congratulations, thanks, considerations, or esteem and prospects for promotion", "I cannot say that my efforts are noticed, appreciated and praised by my superiors".

Likewise, employees are unanimous in saying that the organization does not offer career development prospects. They further state that growth opportunities are very limited despite some training opportunities provided. Some participants expressed the following beliefs: "My work does not allow me to develop myself nor to develop my skills", "My organization offers us some training opportunities to improve our skills".

Furthermore, the work-life balance is not honored. A number of interviewees suggested that "My work does not allow me to maintain a fair balance between my professional and my personal life, whether in terms of time or energy", "My professional life takes precedence over my personal life", "I have no life. As if working all week wasn't enough, I work until late at night and even on weekends. I have time for nothing".

To sum up, most of the circumstances that enhance the emergence of a stressful work environment were identified in the studied work environment. Employees first pointed out that an unhealthy work environment which allows the stress expansion. Employees then report an important workload by having too much responsibilities to accomplish in a limited time.

Since they have a strict workflow to follow and a schedule to stick to, time quickly becomes a source of pressure. Having an important job demand is itself a stressful parameter. But that is not the extent, not having job control possibilities makes the situation more challenging, and thus more stressful.

Performing additional responsibilities has also been extremely stressful to the interviewees. Having to shoulder others' roles makes the employee responsible for tasks which he is not basically responsible for. Furthermore, a lack of social support especially from the hierarchy makes the employee feeling neglected and alone in the face of his daily issues. Relationships being unhealthy, employees must deal with an additional stressful factor. 
Talking about rewards, low wages enhance the feeling of being undervalued and thus, unimportant. To this is added other real struggles lives that have also been identified which are the limited growth opportunities and the difficulties in keeping strict limits between work and the employees' personal. Accordingly, working environment does have a significant impact on the perceived work stress.

\section{The Impact of Occupational Stress on Job Performance}

Taken together, all the results in relation to the job performance point to the same conclusion. Otherwise, employees confirm that working conditions impact their performance and that their performance decreases over time. Some reported that "Working conditions impact my performance", "After two years in this company, I lost the efficiency that I had in my work", "Because of the daily high level of stress, I can't manage to give my best", "I feel that I'm not able to provide the performance that is expected of me", "I can't be able to provide a quality work in a very stressful working environment".

Additionally, employees believe their efforts are undervalued. For example, two interviewees said: "The wages reward level is unsuitable for the efforts that I provide", "The efforts provided exceed the material reward perceived in terms of remuneration, bonus or salary increase", "Even if we try to motived ourselves through the material reward that will be perceived, we end up being disappointed", "A stressful environment combined with a very low rewards lead naturally to a decrease in my individual performance".

Without any exception, all employees report to feel exhausted from work as well as feeling very stressed. These are some of the opinions expressed: "After a day of work, I feel very exhausted", "I often feel very stressed", "I feel overwhelmed and pressed by the time", "I feel some pressure on my shoulders", "I sometimes lack focus and attention", "I am constantly looking for the time left to get out of work", "I feel exhausted from my work", "Occupational stress is an everyday experience", "Some close friends have also noticed that the stress I experience at work has affected my behavior. I have become less sociable and very absent-minded".

A common view amongst interviewees was that the employees believe that their physical and mental health are not good enough, that their behavioral reactions are non-reasonable, and that their cognitive state of mind is overall not very good. As one interviewee put it: "I feel very stressed nowadays. I notice that I tend to be very irritated, nervous and tired". Other added: "I feel that I'm continuously lacking of energy. I deal with a daily headaches and musculo-skeletal pains especially in the upper body", "Not long ago, I was diagnosed with a high blood pressure", "Not even mentioning the decreased concentration and the lack of motivation, it becomes obvious", "The problem is that when we are stressed, our attention drops. And when our attention drops, we notice that our performance drops. And when our performance drops, we try to give even more, but to no avail. This makes us even more stressed and the vicious circle will never stop".

After that, interviewees were asked about their coping strategy. Therefore, employees choose to cope with stress at work by adopting a confrontational attitude as a stress management strategy. While others affirm opting for a positive reassessment stress management strategy. Participants comment as following: "In dealing with a stressful situation, I choose a strategy to confront the source of the problem", "I deal with my problems by facing them", "Usually, I try to put the problem into perspective and not to dramatize", "I opt for a positive reassessment strategy in the face of a stressful situation".

From all above, employees conclude that the general work satisfaction is very limited. It means that the evaluative belief about how much the employees like their job is very low. As some reported: "I feel that the work I do doesn't have a significant value", "I am not proud of my job", "Let me tell you something. I'm ready to accept a lower salary elsewhere with less stressful working conditions. I guess I don't need to say more how much I'm unhappy here". In addition, the sense of belonging to the organization is very limited, leading employees to state that they are still working there more out of obligation. For example, participants said: "I don't feel strong ties of belonging within my organization", "Staying in this organization is a necessity and not a pleasure".

Employees inform thereafter that they are generally not satisfied by their work. They say that they are not considering to stay much longer in the organization. Some employees even say that they wouldn't recommend applying for a job in their organization. Number of statements were recorded as: "All in all, 
and taking all of the aspects into consideration, I'm not happy with my job", "I am very unhappy with my job", "Actually, I am actively looking for another job", "I don't think I will stay in my company any longer", "I will be ready to accept a lower salary elsewhere if this job offers less stressful working conditions", "I certainly do not recommend to a close friend to apply for a job in my company".

To put it concisely, employees describe mainly their work experience in negative terms. Employees report a range of factors which were perceived as causing work stress. It was noticeable that employees confirm their decreasing performance due to work related stress they must deal with. Occupational stress had a major impact on them and on their ability to provide quality services.

Stressful working conditions and stressful work organization affect negatively employees' concentration, motivation and productivity, as well as having negative effects on their health. Experiencing work-stress made employees experiencing serious physical pain. A pain that leads to a loss of personal productivity and work dissatisfaction. Overall, occupational stress does have a significant negative impact on individual performance.

\section{The Impact of Occupational Stress on Customer Value}

The occupational stress, work environment, individual performance, internal management and customer value creation are the main topics covered in the dataset. These themes came up in the discussion regarding whether the work environment is stressful or not, and via what factors?

Through the analysis of the interviews' results, fourteen of the interviewees claimed that they are very committed to satisfying their client demands and needs (theme of customer value creation), whilst a minority argued that they just do their job. The customer is expecting a high quality of service through this project. To satisfy the needs of the customer, the employees are subjected to a daily internal process of control and audit.

Thus, there is a daily issue facing the employees: their work / control is audited by the customer's headquarters in France. Talking about this issue, a common view amongst interviewees was that they are facing a real stress situation regarding the responsibility the employees have in order to provide a quality processed control. A discrete reason emerged regarding this stress situation.

As an interviewee put it, it is monitored by the quality percentage aimed by the customer and the mid manager. The team must achieve a precise quality rate to satisfy not only the needs of the client but also the directives of the management. The employee is subjected to a dual responsibility and thus to a double stress situation.

The following extract shows that even with all the stress difficulties that the employees are facing, all the interviewees reported delivering the controls on due time. Thus, a high quality of service and on-time delivery increases the customer value creation and satisfaction: "I am committed to my work and to my client. Our client is expecting a 97\% of the deliverable quality. If the team doesn't reach this percentage, the whole company is subjected to a penalty. And of course, when the company pays for the low percentage of quality, we don't gain our monthly bonuses. That's why, we give everything to achieve our monthly objective and deliver the control on due time to get our bonuses despite of anything", "We are sometimes the subject of customer complaints".

Through the sixteen interviewees, some employees stated that they are not innovative for their client and they have no added value, while other employees were very positive about being an asset for the client and the project. Linking the quality of service and innovation with the training the headquarters has done for the team, it is possible to say that the employees have developed their competencies and skills as the extract shows below. The Senior management has an enormous role in training, leading and motivating the employees, as an interviewee said: "Thanks to our skills and especially seniority in the methods of control, we go deeper in our analysis and we spot some weak points that helps the client correcting the source of their mistakes and directly target the agencies"

When asked about their performance, the majority of the interviewees are claiming to be very competent and performant when it comes to deliver the contract required quantity and processed quality of the payslip control. Some of the interviewees evaluate their productivity only in terms of the quality they give to the customer. According to an interviewee, the quantity is a parameter but not as important as the 
quality of the control they perform. As interviewees stated: "I find that I am efficient am competent through my productivity level that I find to be good, or even excellent", "My high productivity is mainly due to the quality of the treatment I perform".

Issues related to following-up orders and management were not particularly prominent in the interview data, but a common view among interviewees was that they generally adopt a strategy of satisfying directly the needs of the customer rather than thinking about the directives of the manager. According to interviewees, the manager tends to give more attention to the customer with tons of Visio conferences, meetings and emails rather than pay attention to the employees' needs.

As the extract below shows, the point is that the mid-management gives more attention in what is secondary in doing the work demanded rather than the wellbeing of the employees. As one interviewee put it: "Our manager is more focused on managing absences, delay hours of arrival and the minutes of lunch breaks. The manager never gives any emotional support". And she continues: "My manager gives instructions, explains little, monitors, adopts top-down communication, and limits initiatives, mobilizing a directive management".

In addition, this type of management is impacting directly the mental health of the employees. It gives them more obstacles to deal with rather than focusing one hundred percent on the processed quality of work and on their productivity. As an interviewee put it: to give their best, they need to be at ease in their company. The employees are claiming to be very competent and performant and even if the pace of work is very high, they can achieve their daily and monthly objectives. The only difficulty is dealing with the directives of their mid-management.

As an interviewee stated: "Even if I have a quantitative overload of work, I am competent and I can do my job very well. The main issue I am facing is dealing with my superior in terms of my necessary breaks during all day", "Sometimes I can lose a lot of time during my working hours spending them in the manager office just to explain why I came late in the morning. And this can impact negatively my productivity."

From these data, we can say that the quality and quantity required by the customer is doable. It is not an issue of competencies, skills or even the stressful environment but it's more linked to the midmanagement strategy of monitoring the employees. The employees know very well their commitment to the customer, and they are willing to do whatever it takes to satisfy its needs. They are then committed directly to their customer instead of their manager. Thus, the mid-management has a significant impact on the employees' satisfaction and their productivity.

\section{DISCUSSION}

The employee is the heart of every organization. Without that stakeholder, the organization could not exist and there would be no product or service to sell, and no customer to satisfy. That is why their wellbeing is a major step to achieve the overall organizational performance.

This study examined several aspects of perceived stress among the staff of the multinational company considered. The results reveal a significantly elevated state of stress in the studied population. A high stress level caused by various prevalent complications revealed by the interviewees. It is wise to point out that occupational stress is due either to the way the work is designed, or to the way the organization is managed, or to the both reasons (Cox, et al., 2000).

As outlined by the interviewees, the working environment generates a consequent susceptibility to occupational stress. The working conditions and the work organization afforded to employees are deficient, knowing that every organization must ensure health and safety at work. Factors intrinsic to the work such as stressful conditions or physical threats are one of the most aggravating stressors (Cooper \& Marshall, 1976).

The respondents are unanimous about their accelerated pace of work. A workload that requests a strong intellectual, emotional and physical mobilization. Employees' work is therefore extremely burdensome both physically and psychologically. This means that the employees' capacities, whether cognitive or physiological, are challenged, leading to a generalized exhaustion. 
Employees did not fail to express their frustration over the objectives' definition. This problem also raises another one regarding the way in which task role is distributed. Work pressure, role ambiguity and emotional demands affect the employees' self-efficacy. The role distribution and the responsibility within the organization is considered a main stress factor (Cooper \& Marshall, 1976). A well-balanced task role distribution is thus a fundamental component in the occupational stress control.

These circumstances create a major inherent problem related to the contagious nature of stress. When an employee feels that he or she does not have the necessary resources to meet an environmental demand, he or she naturally tends to transfer this demand to one or many other colleagues. When doing so, he or she transmits his workload to another employee who will, in turn, be overwhelmed. A spiral is therefore set up where a large number of employees will suffer the consequences of their stressed colleague, and will subsequently be stressed as well.

Being able to resist stressful working conditions requires the availability of psychological, intellectual and technical support from the social circle (Karasek \& Theorell, 1990). However, in our study, employees do not report the availability of a social support, neither from superiors nor from colleagues. The impact of a lack of social support has been widely studied within the demand-control-support model (Karasek \& Theorell, 1990). Social support is a response to a help request from the employee in the form of assistance. This will allow the individual to feel less alone and more surrounded, in addition to reducing his or her stress (Cobb, 1976).

Moreover, a mismatched supervision, a poor support, a deficient communication, and an approximate hierarchical behavior all constitute a poor work atmosphere in this multinational company. However, the quality of social relationships between colleagues and towards superiors is an important component in determining the quality of the work climate (French, et al., 1982). Social relationships within the workplace allow an exchange of skills and create an environment suitable for the social and collective management of stressful situations.

Besides the above-mentioned challenges, other difficulties have affected the experience of the employees. A limited job control is one of them. The nature of the work is characterized by a high psychological job demand accompanied by significant efforts to be made, all under limited autonomy. The importance of job control possibilities has been widely investigated especially through Karasek's researches (Karasek, 1979). As described by the author, giving employees an appropriate latitude decision is a way to reduce the tensions resulting from important job demands. Lack of autonomy and non-involvement in the decision-making process is a source of frustration and stress (Karasek, 1979).

Motivation and recognition are the cornerstones of employees' performance. Nevertheless, the study shows that employees do not notice that their efforts are appreciated and praised. An imbalance that leaves employees believing that the compensation they receive does not cover the effort they put in. A stressful characteristic as the effort-reward balance is not being respected (Siegrist, 1996).

The rewards expected from a job are not only monetary, employees also expect recognition for their efforts, social esteem, in addition to a healthy and fulfilling workplace (Jackson \& Schuler, 1995). That is the reason why additional elements have been assessed and whose results have demonstrated a limited career development prospect, a work life imbalance and an important intention to quit the job. These difficulties disturb employees' daily life and affect both their professional and personal lives.

The conjunction of all these elements creates negative emotions and negative work experiences. A negativity that leads to a lack of awareness, restrains cognition, holds flexibility initiatives and limits motivation. It also inhibits the resilience process and obstructs the quick and healthy way of regenerating after a stressful and negative event. As a corollary, employees' productivity is compromised where many have reported a decline in their performance.

Employees accumulate stressors to the detriment of their well-being and fulfillment. This requires a significant daily mobilization of employees' adaptation capacities. An over-solicitation of the adjustment mechanisms causing psychological fatigue to set in. A fatigue that should inevitably be considered, handled and treated.

Otherwise, the employee satisfaction begins when he or she has the necessary autonomy to do the job. As the interviewees have claimed, they can absolutely do the work even with a high pace if they were freer 
to manage their time as they wish. It can be annoying and embarrassing to report every come and go to the sanitary or every movement inside the work place to the manager. Once the employee has been recruited, it means that he or she has the ability to do the job without any supervising. In addition to this, the employee has a small time to take breaks and it is also supervised. The employee knows well the tasks assigned, he or she had the responsibility to deliver on time, so being supervised only gets the situation worse. The autonomy of the employee is his or her satisfaction in this multinational.

"Generals make the decisions but the sergeants run the army" (Tosti \& Herbst, 2009). If this old quote is deeply understood, it can be the key of organization's success. In other words, the managers or supervisors must seek the specific ways to satisfy the needs of the employees. When the employees have an ambient work environment, they give the better version of themselves and thus contribute to the business needs and company goal which is the customer value (Tosti \& Herbst, 2009).

One of the most important traits of the customer satisfaction is the delivery reliability (Bhatti, et al., 2014). Once the contract between the multinational and its client (a B-to-B relationship) is signed, the organization must respect its deadlines. The deliverables are due the $12^{\text {th }}$ of every month. All the payroll controls must have been done and audited internally to be send to the customer. Through the new technologies and the developed IT tools, the client can easily checkup the number of files controlled, their contents, theirs audits and their quality.

Everything is in line, what can be a missing piece of the puzzle is yet the performance of the employee and his or her ability to control all the files assigned during the month. Even if the customer is the brand itself subsidiarized in France, he can still withdraw and cancel the contract at any time. Until now, the only motivation for the employee to deliver in time is the salary bonus and his or her fear to be punished with a malus.

Once the employee is satisfied with all the environment parameters, including the management style, they can give a quality to their product or the service. The employee can be finally performant. The quality is the first need of a customer, and it is a key of success of every organization. The organization who is able to produce quality product or service with a lower cost, wins the game (Tosti \& Herbst, 2009).

The multinational's customer requires $95 \%$ of quality in all the documents controlled. Through the team dashboard, every employee can see the quality percentage through the audit done on his or her payroll controls. It is a matter of competence and trainings received from the day one. If the employee doesn't refer to the French work code, or the references in the internal software and doesn't line up with the instructions, it can be a mistake and thus a decrease of quality. Once again, it is a subject for the managers and team leaders.

The manager must give all the instructions of the clients to the employee, and the team leader must seek their applications within the team. The key to achieve the organizational objectives is learning and growth since it is a topic that affects both the managers and the employees. A topic that also provides the organization with competitive advantage against their competitors and creates innovativeness ((Parmenter, 2009), (Sadler-Smith, et al., 2001), (Rolstadas, 1998), (Utterback \& Abernathy, 1975)). Lack of quality can sometimes be linked to a concentration problem, to a communication and training deficiency, or to a technical support. To the customer, it doesn't matter how the mistake had been done unless it is a new French work code instruction.

Customer satisfaction comes along with the efforts of the management team and of the employees. Once the customer is well treated by the company and the employees, it is possible to say that they reached its satisfaction. Since the customer in our case is framed in a B-to-B business, the customer is satisfied with the quality perceived and the quantity, alias the delivery reliability.

What is provided for the customer is basically intended in the contract. But what about the customer value creation? The customer is in need of some new parameters to enrich his value. If the employees were totally satisfied and their mental health was not neglected, they could have given more value to their customer, and thus, to the brand image and its performance.

All in all, the study revealed that the employees working for this multinational company are overwhelmed with high potential stressors. Employees who consequently suffer from a high level of work- 
related stress and are at risk of burnout. Consequently, stress at work reduces drastically the employees' performance and compromises the organizational health.

Strategically, the performance of this organization is based on the material rewards given to its employees. This type of motivation is the only factor pushing the employees to be performant despite their continuous discomfort in the workplace. Indeed, the customer is satisfied since it's the same brand, but with this type of performance and employee motivation, the customer value creation is missing.

\section{TABLE 2 \\ RESEARCH COMPONENTS OVERVIEW}

\begin{tabular}{cc}
\hline Employee's perceived stress & Customer Value \\
\hline Working conditions & Customer satisfaction \\
Work pace \& Task role distribution & Quality of Service \\
Job demand & Number of complaints \\
Social support \& Relationships' quality & On-Time Delivery \\
Job control & Customer loyalty \\
Coping strategy & Productivity \\
Recognition & Innovation \\
Employee's performance & Managerial relationships \\
Growth opportunities & Output quantity \\
Work-life balance & Customer penalization \\
General health perception & Employee's satisfaction \\
\hline
\end{tabular}

\section{CONCLUSION AND LIMITATIONS}

To conclude, work constraints are a major component in the deterioration of employee health. Although humans do have adjustment capacities to restore their homeostasis after an environmental threat, this capacity was not intended to address the psychological risks arising from difficult working conditions.

In order to know whether difficulties are occurring in the workplace, it is necessary to assess the general health of the employees and identify the existence or not of psychological disorders. Nowadays, we are concerned with "chronic behavioral and social pathologies" and with "bio-behavioral disorders" (Le Moal, 2007). Regretfully, the actual context generates biological and psychological damages and produces a multitude of sufferings that need to be recognized. A recognition that requires a thorough evaluation beforehand.

Evaluation is a mean of objectifying occupational stress. It highlights the signs of its manifestation in the workplace. The evaluation is an indicator that will warn managers against the risk of proliferation of a generalized malaise, naturally leading to a decrease in efficiency. That is why it is also in the companies' interest to identify factors that constitute a risk of stress outbreak. Exacerbating factors, whether physical, cognitive, emotional or social, are those with a duration, intensity and frequency of occurrence that exceed the human coping capacity and resistance limits.

The level of proliferation of the work-related stress within the organization should be assessed in order to objectivize the degree of exposure and plan corrective measures if necessary. Being able to recognize what is really stressing and bothering employees allows avoiding unnecessary stressful situations, allows understanding the triggers for employees' behaviors, as well as having the opportunity to offer assistance to those in need, and it is moreover a sign of a caring management.

Returning to the main objective established at the beginning of this study, it is now possible to state that the occupational stress does impact the individual performance in the case of the studied company. The second major finding is that the individual performance does affect the customer value creation in the studied company.

Mental and psychosocial health is estimated to be an important topic in the United States. Ensuring the health and mental safety for the employees tends to be a priority and a responsibility for the managers and 
the organizations. Nevertheless, there is a significant gap. The mental health and the psychosocial topic are not considered seriously in the developing countries such as Morocco for instance.

Unfortunately, and in order to satisfy the customer's needs which are "delivery reliability" and "quality of the service", the multinational subsidiary in Morocco achieves its objectives by sacrificing the employees' psychosocial health. As Bhatti considered, the multinational focuses more upon the efficiency, and lesser upon the effectiveness (Bhatti, et al., 2014). With this strategy, the organization is putting the employees in the front of the war - if it can be said so - and uses them as resources.

In order to be efficient, the organization uses the most of its resources to produce and sell a service to the customer. But by doing so, the subsidiary in Morocco is involving its brand image as an American multinational working for satisfying the France subsidiary. However, knowing that this multinational is a leader in terms of human resources and recruitment in USA, it can only worsen the brand image, especially in a time where the employees who are the driving force of the company's activities are being mistreated and stressed in a bad management environment in Morocco. Yet - according to our observation within the organization - whether it is in America or in France, the employees are treated better and benefit from with a large range of principles and values which are not applied in Morocco's subsidiary.

Finally, a number of important limitations need to be considered. According to Heckl and Moorman, each organization has to precise the key performance indicators which are relevant and strategic to its singular situation in order to be successful (Heckl \& Moormann, 2010). In our case, since the research study is focused on the American multinational company subsidiarized in Morocco, we evaluated and managed the organizational performance in only two areas as they are the main subjects of our research: employees' satisfaction and customer value creation. The financial sides of the performance are of course important to any organization, but our case is a B-to-B customer relationship and the customer is the same American Multinational subsidiarized in France. Thus, the financial costs and gains are internal and not relevant in our study.

The generalizability of these results is also subject to certain limitations. This is mainly due to the nature of qualitative researches which are, indeed, closer to the studied phenomenon and allow a deeper understanding. But unfortunately, generalizing the results is not an option. This is attributed to the fact that the sample is generally a small convenience sample. That is what quantitative research allows with its larger and more diversified sample. It is through the quantitative study that a greater validation is possible, and thus findings' generalization is allowed.

This study has thrown up several questions in need of further investigation. It would be interesting to compare the stress experiences of employees of other multinational companies subsidiarized in Morocco. Further investigation might explore the human resources management strategies and, therefore, compare the occupational stress manifestations. Another possible area of future research would be to investigate which multinational company ensures that their values are fully maintained in foreign countries.

\section{REFERENCES}

Arnold, J., Cooper, L., \& Robertson, T. (1991). Work Psychology: Understanding Human Behaviour in the Workplace. London: Pitman Publishing.

Atkinson, A.A., Waterhouse, J.H., \& Wells, R.B. (1997). A stakeholder approach to strategic performance measurement. MIT Sloan Management Review, 38(3), 25-37.

Badri, M.A., Davis, D., \& Davis, D. (1994). A study of measuring the critical factors of quality management. International Journal of Quality \& Reliability Management, 12(2), 36-53.

Bhatti, M.I., Awan, H.M., \& Razaq, Z. (2014). The key performance indicators (KPIs) and their impact on overall organizational performance. Quality \& Quantity, 48(6), 3127-3143.

Cobb, S. (1976). Social support as a moderator of life stress. Psychosomatic Medicine, 38(5), 300-314.

Cooper, L., \& Marshall, J. (1976). Occupational sources of stress: A review of the literature relating to coronary heart disease and mental ill health. Journal of Occupational Psychology, 49(1), 11-28.

Cox, T. (1993). Stress Research and stress management: Putting theory to work. Sudbury: HSE Books. 
Cox, T., Griffiths, A., \& Rial-Gonzalez, E. (2000). Research on Work Related Stress. European Agency for Safety and Health at Work. Luxembourg: Office for Official Publications of the European Communities.

De Toni, A., \& Tonchia, S. (2001). Performance measurement systems-models, characteristics and measures. International Journal of Operations \& Production Management, 21(1/2), 46-71.

Esserdi, H., Chaudat, P., \& Mériade, L. (2020). Les risques psychosociaux sur le lieu de travail au Maroc: Une revue de littérature. Yaounde, Congres Institut de l'audit social autour de l'homme et de l'homme au travail.

Everest College. (2009). Workplace Stress on the Rise With 83\% of Americans Frazzled by Something at Work. Los Angeles: Globe Newswire.

Fitzgerald, L., Johnston, R., Brignall, S., Silvestro, R., \& Lewis, R. (1991). Performance Measurement in Service Businesses. The Chartered Institute of Management Accountants éd. London: s.n.

French, J., Caplan, R., \& Harrison, R. (1982). The mechanisms of job stress and strain. New York: John Wiley \& Sons.

Gallup. (2019). Gallup 2019: Global Emotions Report. s.1.

Godin, I., Kittel, F., Coppieters, Y., \& Siegrist, J. (2005). A prospective study of cumulative job stress in relation to mental health. BMC Public Health, 15, 67.

Gosselin, M. (2005). An empirical study of performance measurement in manufacturing organizations. Int. J. Prod. Perform. Manag, 54(5/6), 419-437.

Grippo, A., \& Johnson, A. (2009). Stress, depression and cardiovascular dysregulation: A review of neurobiological mechanisms and the integration of research from preclinical disease models. Stress, 12, 1-21.

Heckl, D., \& Moormann, J. (2010). Process performance management. Dans: Handbook on Business Process Management, pp. 115-135. Berlin: Springer.

Hooke, R. (1678). Potentia Restitutiva, Or of Spring Explaining the Power of Springing Bodies. London: J. Martyn.

International Labour Organization. (2006). Convention No. 187 on occupational safety and health. Geneva.

Ittner, C., \& Larcker, D. (1998). Are nonfinancial measures leading indicators of financial performance? An analysis of customer satisfaction. Journal of Accounting Research, 36, 1-35.

Ivancevich, J., Matteson, M., \& Richards, E. (1985). Who's Liable for Stress on the Job? Harvard Business Review.

Jackson, S.E., \& Schuler, R.S. (1995). Understanding Human Resource Management in the Context of Organizations and their Environments. Annual Review of Psychology, 46(1), 237-264.

Kaplan, R., \& Norton, D. (1992). The balanced scorecard - measures that drive performance. Harvard Business Review, 70(1), 71-79.

Karasek, R. (1979). Job demands, job decision latitude and mental strain: Implications for job design. s.l.: Administrative Science Quarterly.

Karasek, R., \& Theorell, T. (1990). Healthy work. Stress, productivity, and the reconstruction of working life. s.l.: Basic Books.

Kauppinen, K., Kumpulainen, R., Houtman, I., \& Copsey, S. (2003). Gender issues in safety and health at work: A review. Luxembourg: European Agency for Safety and Health at Work.

Lazarus, R. (1995). Psychological stress in the work place. In R. Crandall \& Perrewé (Eds.), Occupational Stress: A handbook (pp. 3-14). London: Taylor \& Francis.

Lazarus, R., \& Folkman, S. (1984). Stress appraisal and coping. New York: Springer Publishing Company.

Lazarus, R., \& Folkman, S. (1988). Manual for the ways of coping questionnaire. New York: Consulting Psychologists Press.

Le Moal, M. (2007). Historical approach and evolution of the stress concept: A personal account. Psychoneuroendocrinology, 32(Suppl 1), S3-9. 
Lefebvre, B., \& Poirot, M. (2015). Stress et risques psychosociaux au travail (2e ed.). Issy-lesMoulineaux: Éditions Elsevier Masson.

Leong, G., Snyder, D., \& Ward, P. (1990). Research in the process and content of manufacturing strategy. Omega, 18(2), 109-122.

Lynch, R., \& Cross, K. (1991). Measure Up! Yardstick for Continuous Improvement. Blackwell éd. Oxford: s.n.

Mapes, J., New, C., \& Szwejczewski, M. (1997). Performance trade-offs in manufacturing plants. International Journal of Operations \& Production Management, 17(10), 1020-1033.

Mathis, R., \& Jackson, J. (2000). Human Resource Management. Ohio: South Western Collage Publishing.

Mental Health Foundation. (2018). Mental health statistics: Stress. s.l.

Miles, M.B., \& Huberman, A.M. (1994). Qualitative data analysis: An expanded sourcebook. Sage éd. s.l.:s.n.

Ministry of Social Development, Solidarity, Employment and Vocational Training. (1999). Decree $n^{\circ}$ 919-99. Morocco.

Morin, E., A., S., \& G, B. (1994). L'efficacité de l'organisation. Montréal: Gaëtan Morin.

Morocco. (2003). Dahir $n^{\circ} 1$-03-194 promulgating the law $n^{\circ}$ 65-99 relating to the Labor Code. s.1.: Morocco.

Neely, A., Gregory, M., \& Platts, K. (2005). Performance measurement system design: A literature review and research agenda. Int. J. Oper. Prod. Manag, 25(12), 1228-1263.

NIOSH. (2014). Stress at work. Cincinnati.

Occupational Safety and Health Administration. (1970). Occupational Safety and Health Act of 1970. s.1.: United States Department of Labor.

Parmenter, D. (2009). Key Performance Indicators: Developing, Implementing, and Using Winning KPIs. New Jersey: Wiley.

Quick, J., Quick, J., Nelson, D., \& Hurrell, J.J. (1997). Preventive Stress Management in Organizations. Washington DC: American Psychological Association.

Rotter, J. (1966). Generalised expectancies for internal versus external control of reinforcement. Psychological Monographs, 80(1), 1-28.

Savoie, A., \& Forget, A. (1983). Le stress au travail : Mesures et prévention. Montréal: Agende d'ARC. Selye, H. (1956). The stress of life. New York: McGraw-Hill Editions.

Siegrist, J. (1996). Adverse health effects of high effort-low reward condition. Journal of Occupational Health Psychology, 1, 27-41.

Sullivan, U.Y., Peterson, R.M., \& Krishnan, V. (2012). Value creation and firm sales performance: The mediating roles of strategic account management and relationship perception. Industrial Marketing Management, 41(1), 166-173.

The American Institute of Stress. (2019). 42 Worrying Workplace Stress Statistics. s.l.

Thompson, P., \& McHugh, D. (1995). Work organisations: A Critical introduction (2nd Ed.). Hampshire: Macmillan Press.

Tosti, D., \& Herbst, S.A. (2009). Organizational Performance and Customer Value. Journal of Organizational Behavior Management, 29(3-4), 294-314.

White, G.P. (1996). A survey and taxonomy of strategy-related performance measures for manufacturing. International Journal of Operations \& Production Management, 16(3), 42-61. 


\section{APPENDIX: INTERVIEW GUIDE}

\section{Topic 1. Presentation of the interviewee}

Job position; Gender; Age; Family situation; Years of seniority.

\section{Topic 2. Work environment and quality of work life}

[1] Tell us about the working conditions in your workplace

[2] Tell us about the work organization provided by your company

[3] Tell us about the task role distribution within your organization

[4] Tell us about social support in your organization

[5] Tell us about your own assessment of your work

[6] Tell us about the growth opportunities offered by your work

\section{Topic 3. Internal management}

[7] Tell us about the organizational flexibility of your organization

[8] Tell us about the workplace relationships in your organization (colleagues and superiors)

[9] Tell us about the rewards offered by your organization

\section{Topic 4. Job performance}

[1] Tell us about your work performance

[2] Tell us about your general work satisfaction

[3] Tell us about the future you foresee regarding your current job

\section{Topic 5. Global health situation}

[4] Tell us about your global health assessment

[5] Tell us about what makes your job stressful

[6] Tell us about your stress management strategies to cope with stress at work

[7] Tell us about your feelings at work

\section{Topic 6. Customer relationship}

[8] Tell us about your relationship toward the organization's customers

[9] Tell us about the quality of your services

[10] Tell us about your productivity

[11] Tell us about your delivery reliability

[12] How can you describe your customer relationship in terms of innovation? 